International Journal of Current Advanced Research

ISSN: O: 2319-6475, ISSN: P: 2319 - 6505, Impact Factor: SJIF: 5.995

Available Online at www.journalijcar.org

Volume 6; Issue 4; April 2017; Page No. 3031-3032

DOI: http://dx.doi.org/10.24327/ijcar.2017.3032.0171

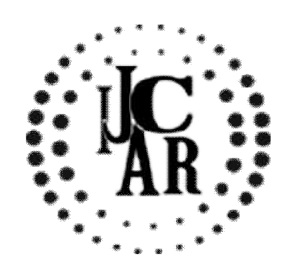

Research Article

\title{
AWARENESS OF INSOMNIA RELATED DISORDERS IN STUDENT COMMUNITY
}

\section{Monisha K, Geetha R.V and Vishnu Priya V}

Saveetha Dental College, Chennai

\begin{tabular}{l}
\hline A R T I C L E I N F O \\
\hline Article History: \\
Received $29^{\text {th }}$ January, 2017 \\
Received in revised form $19^{\text {th }}$ February, 2017 \\
Accepted $22^{\text {nd }}$ March, 2017 \\
Published online $28^{\text {th }}$ April, 2017 \\
\end{tabular}

Key words:

Insomnia, Awareness, Disorders.

\begin{abstract}
A B S T T R A C $\mathbf{C}$
Aim: To conduct a survey and create awareness of insomnia related disorders among students

Objective: To examine the prevalence of risk and create awareness of insomnia related disorders among college students of Saveetha Dental College, Chennai, and their associations with \% calculations.

Materials and Methods: A survey based questionnaire consisting of 12 questions was conducted among 80 students in random in our college.

Results: Insomniac students were comparatively fewer compared to other studies.
\end{abstract}

Copyright $\bigcirc 2017$ Monisha $\mathbf{K}$ et al. This is an open access article distributed under the Creative Commons Attribution License, which permits unrestricted use, distribution, and reproduction in any medium, provided the original work is properly cited.

\section{INTRODUCTION}

Insomnia is a symptom of a sleeping disorder characterized by a persistent difficulty falling asleep or staying asleep despite the opportunity. The lack of sleep can make classes and challenges more difficult to complete for students. Insomnia has become more and more common, and the effects are extremely negative to a student's education. Research on sleep disturbances in undergraduate medical students is of particular interest because of the known relationship between sleep and mental health [1] and the concern that the academic demands of medical training can cause significant stress.[2]

Insomnia is nowadays being recognised as a public health concern which affects the of life of millions of people around the world as it can lead to long-term physical and mental exhaustion with altered mood, concentration, and memory.Inadequate sleep quantity and quality have been associated with poor school performance, mental health problems, poor sociability, behavioural problems, the development of obesity and its accompanying comborbidities in adolescents [3]. Sleep disorders such as Obstructive sleep apnea (OSA) syndrome is characterized by repetitive episodes of upper airway obstruction that occur during sleep, usually associated with a reduction in blood oxygen saturation [4] is a common complication which affects the population worldwide.[5]Subsequently, the social and professional aspects of life are also being affected because of a deterioration of general condition with a decrease in intellectual abilities and cognitive behaviour. This study aims to assess the risk of insomnia related disorders and create awareness among the students of the same.

*Corresponding author: Monisha K

Saveetha Dental College, Chennai

\section{MATERIALS AND METHODS}

The survey based questionnaire was conducted among 80 students aged 17-21 in random of Saveetha Dental College, Chennai.

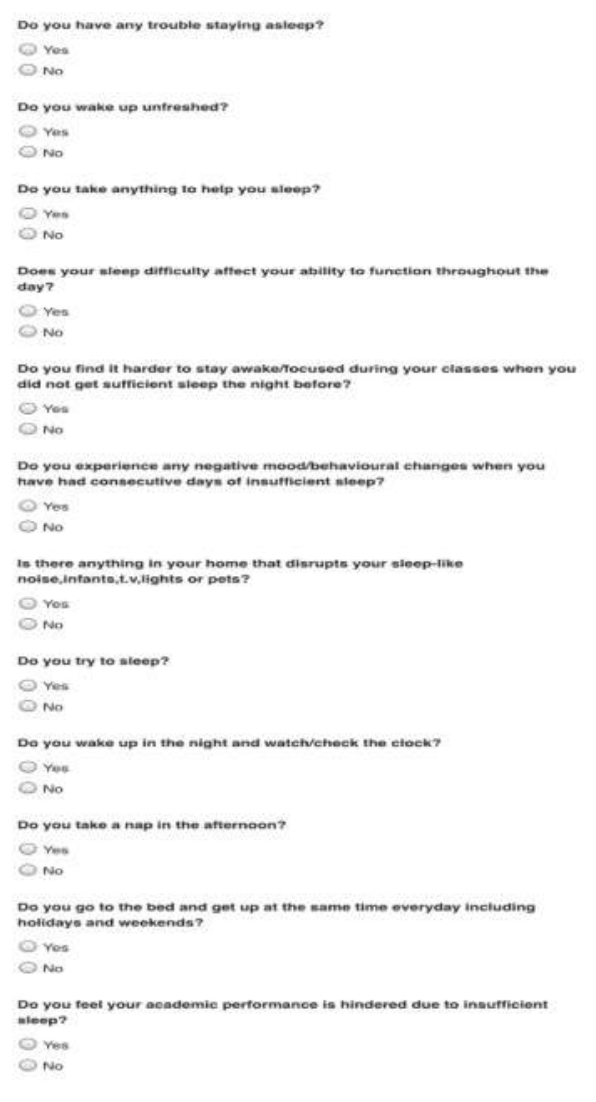

Fig 1 Survey questions given to the participants. 
The questionnaire consisted of 10 yes or no choice questions. Students \% calculations were calculated as insomniac if their answers were yes for more than 5 questions. Bar graphs and pie charts are charted for the respective findings.

\section{RESULTS}

Among the 80 students chosen in random who participated in completing the survey is likely to have sufficient and healthy pattern of sleep in normal. From this study, following three were taken into considerations charted on a bar graph and piechart.

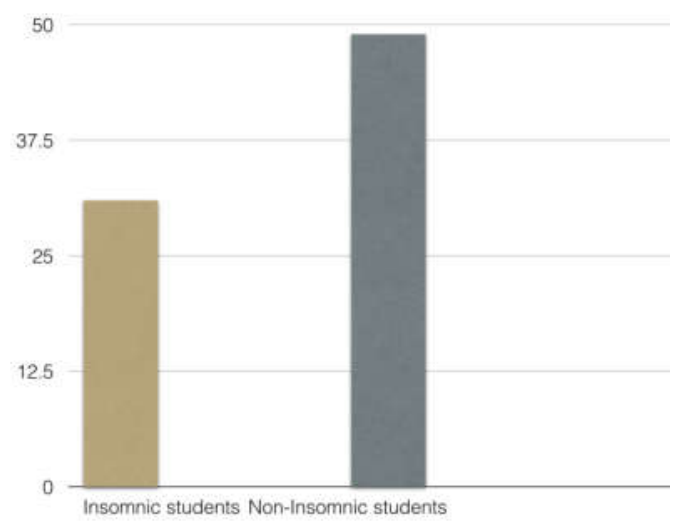

Fig 131 out of 80 students when analysed were insomniac and the rest 49 were not insomniac and maintained a healthy sleep pattern.

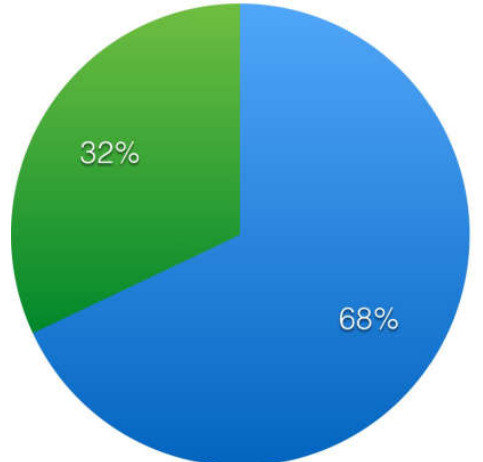

Fig $268 \%$ of students found it harder to stay focused during classes when they did not get sufficient sleep the night before.

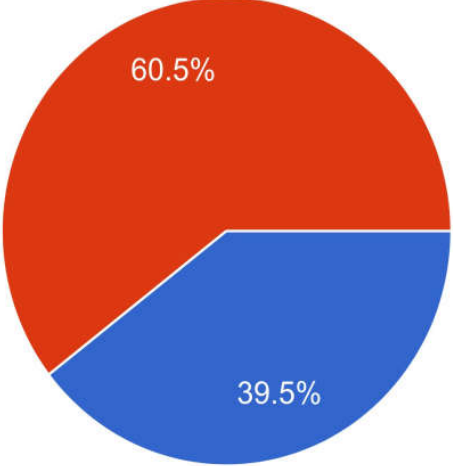

Fig $360.5 \%$ of students reported that their academic performance is being hindered due to insufficient sleep.

\section{DISCUSSION}

Individuals with family histories of depression or anxiety and who manifest lifelong depression and anxiety beginning in childhood are at uniquely high risk for insomnia at midlife [6]. A few studies suggest that anxiety may be a risk factor for future insomnia. [7]
Moreover, a considerable number of researches documented a high prevalence of sleep problems among clinically-anxious youth $[8,9]$ as well as elevated levels of anxiety and stress in university students. [10] Caffeine consumption among adolescents have also increased dramatically the past decade.[11] This causes decreased performance in classroom, sleep deprivation and viewing the addictive properties and acceptance of caffeine as a gateway drug.[12] Narcolepsy followed by restless legs syndrome/periodic limb movement disorder, circadian rhythm disorder, affective disorder, obstructive sleep apnea, and hypersomnia are associated disorders of insomnia.

\section{CONCLUSION}

This study concludes that not many students are at a higher risk of being insomniac but are maintained with sufficient and healthy sleep pattern and also this study will help create awareness among the students who are likely to be insomniac about related disorders that impact lifestyles.

\section{References}

1. Kim EJ, Dimsdale JE, authors. The effect of psychosocial stress on sleep: a review of polysomnographic evidence. Behav Sleep Med. 2007;5:256-78. [PubMed Central][PubMed]

2. Abdulghani HM, Alrowais NA, Bin-Saad NS, AlSubaie NM, Haji AM, Alhaqwi AI, authors. Sleep disorder among medical students: relationship to their academic performance. Med Teach. 2012;34 Suppl 1:S37-41. [PubMed]

3. Rene Jochebed. S et al /J. Pharm. Sci. \& Res. Vol. 7(6), 2015, 381-384

4. C.Sunitha, S.ArvindkumarS. Obstructive sleep apnea: Clinical and diagnostic features. Indian $J$ Dent Res 2009;20:487-91

5. Ankit Mehta, PadmaAriga, Diagnosis and Management of obstructive sleep apne.J Bio Sci Opinion 2014;2(5):310-315

6. Goldman-Mellor S, Gregory AM, Caspi A, Harrington H, Parsons M, Poulton R, et al. Mental health antecedents of early midlife insomnia: evidence from a four-decade longitudinal study. Sleep. 2014;37(11):1767-75. doi: 10.5665/ sleep.4168 [PMC free article] [PubMed]

7. Jansson M, Linton SJ. The development of insomnia within the first year: a focus on worry. British journal of health psychology. 2006;11(Pt 3):501-11. [PubMed]

8. Forbes EE, Bertocci MA, Gregory AM, Ryan ND, Axelson DA, Birmaher B, et al. Objective sleep in pediatric anxiety disorders and major depressive disorder. J AmAcad Child Adolesc Psychiatry. 2008; 47(2):148-55. doi: 10.1097/chi.0b013e31815cd9bc [PMC free article] [PubMed]

9. Storch EA, Murphy TK, Lack CW, Geffken GR, Jacob ML, Goodman WK. Sleep-related problems in pediatric obsessive-compulsive disorder. $J$ Anxiety Disord. 2008;22(5):877-85. [PMC free article] [PubMed]

10. Royal college of psychiatrists, Mental health of students in higher education. London: 2011.

11. Priadarsini.T., Gayatri devi, Asian J PharmClin Res, Vol 9, Suppl. 3, 2016, 149-151. 